\title{
Analysis Causes of and Solutions for Urban Water Logging in Shijiazhuang
}

\author{
Qiangqiang $\mathrm{Li}^{1} \mathrm{a}^{*}$, Hongwei $\mathrm{Li}^{2}$ \\ 1. 2 Urban and Rural Construction College, Agricultural University of Hebei, Baoding, China \\ a13333389360@163.com
}

Keywords. Urban water logging, Shijiazhuang, Underground pipeline tunnel system, Sponge city.

\begin{abstract}
Urban water logging has caused loss of life, injuries of personnel, and economic loss in many large and medium sized cities in recent years. This paper, to provide more solutions for urban waterlogging prevention and control in China, takes Shijiazhuang as its research object; concludes the causes of water logging by analysing different factors like geography, climate characteristics, and urban construction in Shijiazhuang; and then brings forward the differentiated solutions-like perfecting rain-caused flood safety system, perfecting the drainage system, establishing underground pipeline tunnel system, and building the "sponge city"-in different situations.
\end{abstract}

Urban water logging refers to the waterlogging disaster caused by low drainage ability but heavy rainfall or continuous precipitation in urban areas. In recent years, many medium and large-sized cities in China have been attacked by heavy rains and then water logging disasters. The water logging caused by heavy rain in Guangzhou on May $7^{\text {th }}, 2010$; in Nanjing on July $18^{\text {th }}, 2011$; and in Beijing on July $21^{\text {st }}$, 2012 are the cases. On July $19^{\text {th }}$, 2016, Shijiazhuang, the capital city of Heibei province, suffered a widespread heavy rain, causing serious problems: traffic tie-up due to road water logging, tunnel water logging and bridge water logging in multiple locations; black-out in many places across the city; potable water pollution; village drowning; and loss of lives. The urban water logging caused by heavy rain has cost Shijiazhuang many lives and financial loss and bring the problem of urban water logging into the picture.

Table 1 shows the information about waterlogging in 351 cities since 2008; these cities are hit by waterlogging frequently with high water depth and long duration. Urban water logging problems has been pushed to live in the city of each individual and thought-provoking. To provide more solutions for urban waterlogging prevention and control in China, this paper takes Shijiazhuangcapital city of China's Hebei province - as its research object, concludes the causes of water logging by analysing different factors, and then brings forward the pragmatic and feasible solutions.

\begin{tabular}{|c|c|c|c|c|c|c|c|c|c|c|}
\hline \multirow{2}{*}{$\begin{array}{c}\text { Urban } \\
\text { water } \\
\text { logging }\end{array}$} & \multicolumn{3}{|c|}{$\begin{array}{l}\text { Number of } \\
\text { occurrences } \\
\text { (Piece) }\end{array}$} & \multicolumn{3}{|c|}{$\begin{array}{c}\text { Maximum } \\
\text { water depth } \\
(\mathrm{mm})\end{array}$} & \multicolumn{4}{|c|}{$\begin{array}{c}\text { time of duration } \\
\text { (h) }\end{array}$} \\
\hline & $1 \sim 2$ & $\geq 3$ & $\begin{array}{c}\text { Tot } \\
\text { al }\end{array}$ & $\begin{array}{c}15 \sim \\
50\end{array}$ & $\geq 50$ & $\begin{array}{c}\text { Tot } \\
\text { al }\end{array}$ & $\begin{array}{l}0.5 \\
\sim 1\end{array}$ & $\begin{array}{c}1 \sim 1 \\
2\end{array}$ & $\geq 12$ & $\begin{array}{c}\text { Tot } \\
\text { al }\end{array}$ \\
\hline $\begin{array}{l}\text { Quantity } \\
\text { of urban }\end{array}$ & 76 & 137 & 213 & 58 & 262 & 320 & 20 & 200 & 57 & 277 \\
\hline $\begin{array}{c}\text { Urban } \\
\text { proportio } \\
\mathbf{n} \\
\end{array}$ & $\begin{array}{l}22 \\
\%\end{array}$ & $\begin{array}{l}40 \\
\%\end{array}$ & $\begin{array}{c}62 \\
\%\end{array}$ & $\begin{array}{l}16 . \\
5 \%\end{array}$ & $\begin{array}{l}74 . \\
6 \%\end{array}$ & $\begin{array}{l}91 . \\
1 \%\end{array}$ & $\begin{array}{l}5.7 \\
\%\end{array}$ & $\begin{array}{l}57 . \\
0 \%\end{array}$ & $\begin{array}{l}16 . \\
2 \%\end{array}$ & $\begin{array}{l}78 . \\
9 \%\end{array}$ \\
\hline
\end{tabular}

Table 1 Waterlogging in 351 cities in China since 2008

\section{Causes of urban water logging in Shijiazhuang}

1.1 Intense time-space rainfall caused by the climate and geographical factors. Dominated by continental monsoon, Shijiazhuang features an unevenly-distributed rainfall which is highlyconcentrated in the flood season from June to September. Therefore, the city can be an easy target 
in the flood season when there are a lot of rains, even heavy ones in a short time. And heave rain in short time can be the direct cause of the city's water logging problem.

As for the geographical condition, Shijiazhuang is high in the west and lower in the east. The west features high mountains, steep cliffs and narrow valleys, thus being easily stricken by debris flows and flash floods in rainstorms. The downtown area and the plains are flat with little elevation difference in topography, thus causing poor drainage in heavy storms which waterlogging in the places such as overpasses and road intersections in the city and flood in the plain under the feet of mountains.

1.2 Poor drainage caused by poor design of drainage pipeline. Old drainage system in Shijiazhuang cannot meet the demand of city expansion and development. The city has enlarged from 87 to 278 square kilometers in the past 20 years; however, some of its drainage pipelines features aging problem, low standard in design, small diameter, and limited drainage ability, thus being easy to cause the water logging problem in the low-lying areas and the higher drainage pressure for these pipeline. Although the rainwater and sewage discharge system has been gradually formed in the $2^{\text {nd }}$ and $3^{\text {rd }}$ Rings, it still cannot meet the drainage demand due to the incomplete drainage pipeline system.

1.3 Increasing surface runoff caused by enlarging urban impervious area. The rapid urbanization is an important cause of water logging disasters for it changes the natural hydrological conditions and even destroys the natural water cycle process. The increasing impermeable areas like pavements, squares and roads in the city weakens the soil infiltration performance, causes increasing surface runoff, and make flood hydrograph in a sharp and steep way, which all increase the pressure of city flood prevention and control system. As Figure 1 suggests, the runoff coefficient is in proportion with the impervious area. Figure 2 shows that the total flood volume is in proportion with the impervious area. Therefore, the other key factor causing urban water logging is the increasing surface runoff due to the enlarged impervious area.

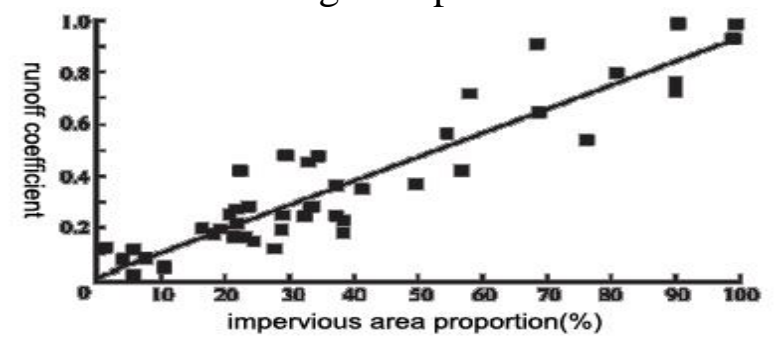

Figure 1. Relation between the runoff coefficient and the impervious area in city

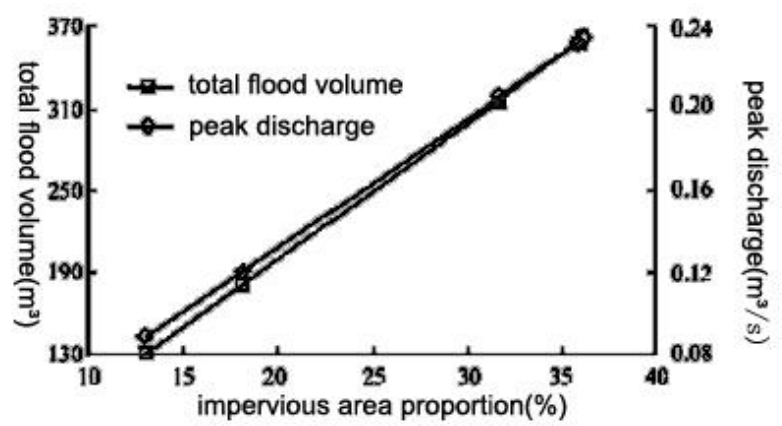

Figure 2. Relation between the total flood volume and the impervious area in city

1.4 Poor capacity in absorbing rain-caused flood. Urban rain-caused flood is mainly absorbed by two kinds of waters: the waters for regulation and storage of flood; and the water bodies in the city which connect lakes and other water system. Construction during the urbanization includes city transformation and new town construction. The former can easily reduce the size of the water body, the greened land, and the flood detention area due to economic reason while the latter requires flatten the land and then build fundamental systems like water supply, flood drainage, and electricity supply, thus will inevitable carry out the landfill projects and reduce the city's flood absorption capacity. 


\section{Solutions for urban water logging}

2.1 Perfecting rain-caused flood safety system. Water logging problems might occur during heavy rains in some low-lying areas such as underground bridges and roads due to the city's poor rainwater discharge capability and its poor flood safety system.

The rain-caused flood safety pattern can be determined based on the analysis on the surface runoff process and the rain-caused flood drowning area when faced with the heavies possible rainfall in a 20-year, 50-year, and 200-year periods. Just as Table 2 shows, the depth and time of flood can be different in different situations. Therefore, the rain-caused flood safety system can be established by building a better underground pipe network system, effectively maintain the natural process of surface runoff, and restore the flood regulating and storage ability. In this way, the city can be protected from the rain-caused water logging.

\begin{tabular}{|c|c|c|c|}
\hline $\begin{array}{c}\text { Depth of flood (m) } \\
\text { Time of flood (min) }\end{array}$ & $\mathbf{0 - 3 0}$ & $\mathbf{3 0 - 6 0}$ & $\begin{array}{c}\mathbf{6 0 -} \\
\mathbf{1 2 0}\end{array}$ \\
\hline $\mathbf{0 . 1 5} \mathbf{0 . 2}$ & 1 & 1 & 2 \\
\hline $\mathbf{0 . 2 \sim 0 . 4}$ & 2 & 2 & 3 \\
\hline$>\mathbf{0 . 4}$ & 3 & 3 & 3 \\
\hline
\end{tabular}

Table 2 Time and Depth of Flood

2.2 Perfecting drainage system. The process of perfecting the drainage system is to upgrade the existing drainage systems and establish new drainage systems.

Rain sewage diversion in Qiaoxi District is a must which can release the pressure of Qiaoxi Sewage Treatment Plant, reduce the sewage treatment cost, and beautify people's living environment; for the city's northwest part, drainage system improvement needs to be carried out for it has the city's longest drainage pipeline and the drainage facilities of the largest water collecting capability. Therefore, the existing pipelines should be upgraded to meet the drainage requirements of the city; as for the East Ring, a water discharging project needs to be established. The East Ring's discharging pressure is on the underground drainage ditches considering the economic elements for the special economic zone was built there.

2.3 Establishing underground pipeline tunnel system in a comprehensive way. solve the urban water logging problem, the measures of perfecting and establishing drainage systems now are far from enough; the best choice should be establish underground pipeline tunnel system in a comprehensive way. This is a smooth conclusion drawn from the city of Paris - a rainy city never confronts water logging and traffic tie-up in heavy rains.

Shijiazhuang has already put the construction of comprehensive underground tunnel system into its calendar: Zhengding New District is to start its construction at the end of 2016 and put the system into use at the end of 2020; other districts and counties in Shijizhuang also need to build their own underground tunnel system according to their own conditions and strive to put it in service at the end of 2020 .

Shijiazhuang is to define demonstration areas of the comprehensive underground tunnel system and Zhengding New District is the downtown area of the city. Other districts should define their demonstration areas based on their conditions, and then make a plan for the establishment of the underground tunnel system. The old city areas need to combine the urban renewal with projects like road improvement, channel upgrading, railway and road construction, as well as underground space development; and build their own underground tunnel system in a comprehensive way. 
2.4 Building Shijiazhuang into a "sponge city". jiazhuang city is located in warm temperate semi-humid continental monsoon climate zone, thus being a dry place with few rainfalls; the Hutuo River in the north of the city has gone dry all year around; also, the downtown area of the city is in lack of greening land areas and natural water systems, thus being with poor climate regulation ability.

Establishing underground pipeline tunnel system in a comprehensive way is undoubtedly one of the most direct and effective methods to solve the problem of urban water logging and the phenomenon of "ocean sightseeing". But this method cannot be fruitful in a short term and the need for money can be huge; the unlimited short-terms projects of expanding underwater pipelines is definitely not a proper means for solving the water logging problem. Therefore, the concept of "sponge city" stands out seems to be the most efficient right now.

According to Construction Technical Guide for a Sponge City released in 2014, "sponge city" refers to the city which can function like a sponge; it shows flexibility facing environmental changes and natural disasters by absorbing, storing, penetrating and purifying water during rainy times and releasing water in times of few rainfalls. By building a sponge city, Shijiazhuang can make itself a city which deals with urban water logging in an ecological way; what's more, the city can effectively employ the rain and flood resources and pursue an environment friendly approach. Figure 3 gives a clear point about the advantage of sponge city in controlling the surface runoff compared with the traditional city.

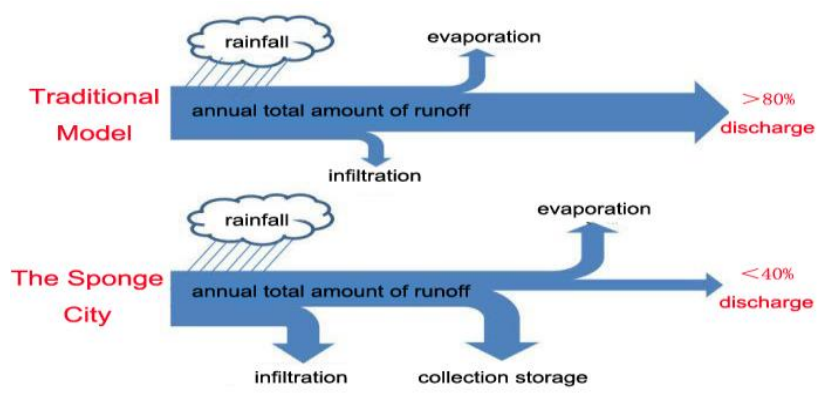

Figure3. Surface runoff control in traditional city and sponge city

2.4.1 Improving squares, roads and urban structures. ording to Table 3, the surface runoff which is directly influenced by the structures on the ground is in proportionate with the number of floods and water logging disasters. Therefore, to reduce urban water logging and building sponge city, squares, roads and urban structures need to be improved.

Table 3 Land usage and surface runoff coefficient

\begin{tabular}{|l|c|}
\hline \multicolumn{1}{|c|}{ Land usage } & $\begin{array}{c}\text { Surface } \\
\text { runoff } \\
\text { coefficien } \\
\mathbf{t}\end{array}$ \\
\hline Roads & 0.85 \\
\hline Buildings & 0.9 \\
\hline Arable land & 0.3 \\
\hline Green roof & 0.15 \\
\hline
\end{tabular}

Improving city squares and roads can be carried out in this way. As for the pavement design, traditional cement pavements and asphalt pavements cannot store the rain; but with some permeable materials, this can be changed. For instance, some parks in the city can use the permeable concrete to lay the pavements; in the rainy days, water can penetrate the road and be held under it while in 
hot summer days, the stored water can get out and create a cool atmosphere. People can feel the differences by standing right onto the road with new materials. This is the effect of sponge. And the materials with the same effects like permeable bricks, ecological concrete materials, and coloured permeable concrete materials has now been widely used.

As for the road green belts, the dented spots or sands and stones have been installed on them to receive water and recharge of groundwater through soil.

Improving the urban structures can be carried out by promoting green roofs and rainwater collection facilities. The rainwater in the urban structures can be separated into grey water and black water; and the former can be recycled toilet flushing. The rainwater collected using the permeable green roofs or the rainwater collection tank can be purified for fire fighting and other emergent cases. By designing a dual-way water system, the building can produce toilet flushing water with grey rainwater and the collected rainwater. In this way, people can save water in a recycling way, indicating the low impact development.

2.4.2 Building Minxin River. nce 1997, Shijiazhuang has invested a lot of money to build Minxin River. As a part of Shijiazhuang's sponge city system, the River has been purified in various ways for industrial production, municipal use, and landscape usage to reduce the pressure on the city's water resources. Secondly, the River is built with landscapes on its bank which cultivates water plants to purify the water and for sightseeing.

2.4.3 Constructing wetland park. and has been believed as "the kidney of the earth" by environmental experts for it can help to dissolve the harmful materials so as to purify the water and to form a complete ecological balance system.

Shijiazhuang can build its water-themed parks like Water Park, Chang'an Park, and Century Park in to sponge-like wetland parks. In this way, these wetland parks can function not only as beautiful tourist attraction but also as a mechanism to adjust urban rain-caused flood, utilize water resources in a comprehensive way, recharge groundwater, regulate urban climate, and reduce the heat island effect.

As for the construction of wetland parks, four technical points are the keys: building a "green sponge system" based on the rain-caused flood pattern in the city; forming a "sponge-like terrain" with landfilling and land digging techniques; establishing a multifunction wetland system; and combining the function of wetland parks with the local plants and animal protection, local tourism and local education.

\section{Conclusions}

The city's poor drainage system is the main reason for urban water logging in Shijiazhuang. And to solve the problem, the author put forward several approaches including perfecting rain-caused flood safety system and the drainage system, establishing underground pipeline tunnel system, and building Shijiazhuang into a "sponge city". The author hopes to build Shijiazhuang a city which can pass the test of heaviest possible rains and to provide other cities in China some feasible methods to deal with their waterlogging problems.

\section{References}

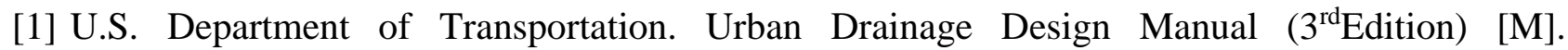
Washington: Hydraullics Engineering Publication (2009)

[2] Yu Kongjian. Coexisting of the Architecture and the Flood: the Qunli Park in Harbin City [J]. Architectural Journal, 2012(10):62-69.

[3] Mo Lin, Yu Kongjian. Structure the Urban Green ponge: Study on Planning an Ecological Stormwater Regulation System[J]. Urban Development Studies, 2012,19(5):4-8.

[4] Xiao-xin Zhang, Wang Qiang, Fu Zheng. Research on Urban Waterlogging Control Standard in Foreign Cities. Beijing Planning and Construction. 2012 (5) : 70-73. 
[5] Xing-jun Liu. Urban Rain Pollution Renovation Practice Analysis. Urban Construction Theory Research. 2012 (16) : 1-4.

[6] Li Siwei. Discussion on Several Problems in Construction of Urban Underground Pipeline Information Management System [J]. 3s World, 2005(10) : 28 and 29.

[7] Xiao-li Hao. Introduction to Problems and Countermeasures in Shijiazhuang's Drainage System. Water Resources Development and Management. 2016 (1) : 8-10.

[8] Zhou Hui, Hao Lin, Li Yangang. Shijiazhuang city "2012-7" storm flood analysis. Water science and engineering technology. 2013 (1) : 13 to 15.

[9] Hu Qian, Sun Jing, Cao Likun, the urban rainwater landscape facilities construction and retrofit [J]. Chinese garden. 2007, 23 (10) : 66-72.

[10]Xing Wei Zhao Dongquan, Ji-ning Chen, etc. Sustainable Urban Rainwater System Based on the low impact development [J]. China Water Supply and Drainage. 2011, 27 (20) : 13 to 16. 